\title{
The auto-ignition of single $n$-heptane/iso-octane droplets
}

\author{
R. Stauch*, U. Maas \\ Institut für Technische Thermodynamik, Universität Karlsruhe (TH), Kaiserstrasse 12, D-76128 Karlsruhe, Germany
}

Received 6 April 2006; received in revised form 14 November 2006

Available online 28 February 2007

\begin{abstract}
Numerical simulations including detailed chemical and physical models are performed to investigate the influence of different physical parameters on the auto-ignition of $n$-heptane/iso-octane droplets in air. Simulations are performed for isobaric conditions with an ambient pressure of 8 bar and a droplet radius of $200 \mu \mathrm{m}$. The ambient gas temperature ranges from $800 \mathrm{~K}$ to $2000 \mathrm{~K}$ and the droplet temperature was varied from $300 \mathrm{~K}$ to $400 \mathrm{~K}$. Below an ambient temperature of $1000 \mathrm{~K}$ the ignition delay time is found to increase with an increasing volume fraction of iso-octane. Above $1000 \mathrm{~K}$ the ignition delay time appears to be almost independent of the mixture composition of the droplet. The local ignition conditions are also studied. It turns out that ignition occurs at points, where the mixture is lean. This trend is more significant, if the ambient temperature increases. The influence of physical properties of the mixture components, like diffusion coefficients, heat conductivity, heat of vaporization and vapor pressure, is investigated. Furthermore, the influences of simplifying assumptions such as the distillation and diffusion limit are studied.
\end{abstract}

(c) 2007 Elsevier Ltd. All rights reserved.

Keywords: Droplet; Multicomponent; Ignition; $n$-Heptane; iso-Octane

\section{Introduction}

A reliable description and simulation of spray combustion requires a detailed understanding of the underlying physical and chemical processes. Detailed simulations of these processes help to test and to validate assumptions made in the simulation of spray combustion [1-5]. The ignition and combustion of single fuel droplets in a stagnant gas environment is well suited to investigate the basic principles of droplet combustion. Because of these conditions spherical symmetry can be assumed. This regime is appropriate to investigate the basic physical and chemical processes, like vaporization, molecular transport and chemical kinetics and their interaction. Particularly for describing transient processes like the ignition of the droplet a detailed understanding of this interaction is necessary. In order to achieve such a detailed understanding, it is of

\footnotetext{
* Corresponding author. Tel.: +49721608 8743.

E-mail address: stauch@itt.mach.uni-karlsruhe.de (R. Stauch).
}

importance to investigate the influence of certain physical parameters on the ignition process.

Single component droplets are not representative for practical applications, because almost all fuels consist of mixtures of hydrocarbons. The modeling of multicomponent fuel droplets is much more ambitious because additional physical processes have to be accounted for. Diffusion inside the droplet might affect the vaporization process and therefore the ignition delay time or the droplet lifetime significantly. Furthermore, a detailed multicomponent vaporization model has to take into account the different vapor pressures of the species and the different enthalpies of vaporization.

Several authors have investigated the ignition and combustion of multicomponent fuel droplets. A number of studies deal with the combustion of droplets of fuel and water [6-9]. Makino and Law have investigated the gasification behavior of burning and vaporizing dodecane/hexadecane droplets [10]. Okai et al. and Shaw et al. have studied the combustion of methanol/dodecanol droplets experimentally $[11,12]$. The ignition of blended fuel 


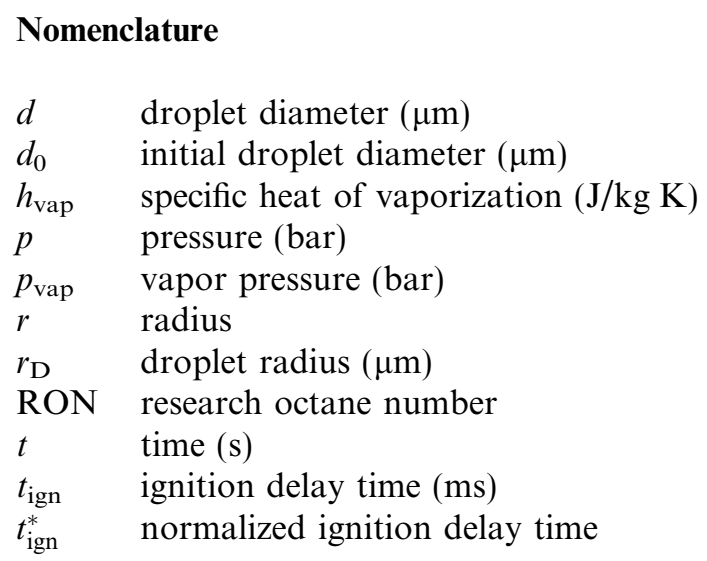

\begin{tabular}{|c|c|}
\hline$T$ & temperature $(\mathrm{K})$ \\
\hline$T_{\mathrm{D}}$ & droplet temperature $(\mathrm{K})$ \\
\hline$T_{\mathrm{G}}$ & gas temperature $(\mathrm{K})$ \\
\hline \multicolumn{2}{|c|}{ Greek symbol } \\
\hline$\lambda_{\mathrm{loc}}$ & local air-fuel ratio \\
\hline \multicolumn{2}{|c|}{ Subscripts } \\
\hline $\mathrm{C}_{7} \mathrm{H}_{16}$ & $n$-heptane \\
\hline $\mathrm{C}_{8} \mathrm{H}_{18}$ & iso-octane \\
\hline
\end{tabular}

$T \quad$ temperature (K)

Greek symbol droplets, consisting of $n$-heptane and $n$-hexadecane, has been investigated by Takei et al. [13].

In this study the ignition process of $n$-heptane/iso-octane droplets is investigated in detail. Previous research, using the present numerical model, was on the ignition behavior of pure $n$-heptane droplets [14]. With the extension to multicomponent droplets consisting of $n$-heptane and isooctane it is possible to simulate droplets with a given research octane number (RON). Here, the influence of the mixture composition on the ignition delay time is investigated for different ambient temperatures. The local airfuel ratios of the $n$-heptane/iso-octane mixture at the starting point of ignition are determined for a wide range of ambient temperatures. Furthermore, it shall be studied, if the modeling of a gasoline droplet by a bicomponent droplet, consisting of $n$-heptane and iso-octane, with the corresponding RON leads to reasonable results. Such a modeling can be crucial, because real gasoline consists of a multitude of chemical species with different physical and chemical properties. The physical properties of two mixtures can vary significantly, even though the RONs are equal. Thus, the influence, in terms of sensitivities, of some physical properties, e.g. vapor pressure and heat of vaporization, on the ignition process is investigated. Furthermore, the results of calculations based on detailed modeling of the transport processes in the liquid phase are compared to the results of simulations with almost infinitely fast diffusion (distillation limited vaporization) and with artificially decelerated diffusion (extremely diffusion limited) in the droplet. The validity of the used numerical model has been demonstrated in [14].

\section{Numerical model}

To investigate the coupling of physical and chemical processes, detailed simulations have to be performed. The chemical and the physical processes are modeled in detail. The chemical kinetics is governed by a large number of chemical species and elementary reactions. In our case of mixtures of $n$-heptane and iso-octane the reaction mechanism of Ahmed et al. [15] is used, comprising 94 chemical species and 614 elementary reactions. The physical transport processes in the gas phase as well as in the liquid phase are modeled in detail. Fourier's law is used to determine the heat fluxes [16]. For the calculation of the diffusion coefficients the approximation of Curtiss and Hirschfelder [17] is used. The mixture of the liquid fuels $n$-heptane and iso-octane is assumed to be ideal. The liquid phase properties are calculated based on the data correlations taken from Reid et al. [18]. The density of the liquid fuel is determined by the relation of Hankinson and Thomson [19]. The approximation of Latini and Baroncini [20] is used to calculate the heat conductivities, the Rowlinson-Bondi method [21] to calculate the specific heat capacities. The diffusion coefficients are determined by the approximation of Tyn and Calus [22]. For the calculation of the liquid viscosities the correlations of Brulé and Starling and Letsou and Stiel [23] are used. The presence of internal circulation in the liquid phase is ignored. Previous studies showed no significant influence of the internal circulation on the reported results. These observations are in accordance with the findings of Cuoci et al. [24].

The vaporization model is based on a local phase equilibrium. A detailed description of the governing equations and the interface equations of the phase transition can be found in [14]. In the presented case of $n$-heptane/iso-octane droplets, surface reactions are not taken into account. The necessary properties to model the phase transition are also taken from Reid et al. [18]. The vapor pressure is calculated using the Wagner equation [25], the enthalpy of vaporization is calculated by the approximation of Riedel and Watson [26-28].

To overcome numerical difficulties due to the discretization of the convective terms, the equation system is transformed into modified Lagrangian coordinates. Uniform pressure is assumed, and therefore the momentum conservation equation is fulfilled trivially [29]. The governing equations of the liquid and the gas phase are solved in a fully coupled way. Efficient numerical methods are utilized to minimize computing time $[29,14]$. The partial differential equation system is discretized by the method of lines using finite difference techniques. The solution of the resulting 
differential-algebraic equation system is calculated by the linearly implicit extrapolation method LIMEX [30]. A detailed description and validation of the numerical model can be found in [14].

\section{Results and discussion}

Detailed simulations are performed for isobaric conditions at an ambient pressure of 8 bar. The fuel droplets consist of different mixtures of $n$-heptane and iso-octane.

\subsection{Ignition delay times}

Ignition delay times are calculated for ambient gas temperatures ranging from $700 \mathrm{~K}$ to $2000 \mathrm{~K}$. In Fig. 1 the temperature dependence of the ignition delay time for different $n$-heptane/iso-octane mixtures is shown. The typical exponential increase of the ignition delay time with decreasing ambient temperature is obtained. Below $1000 \mathrm{~K}$ the slope of the curve changes, which can be explained by the change of the active chemical pathways for chain branching [31]. For high temperatures above $1000 \mathrm{~K}$ the ignition delay times are almost the same for different research octane

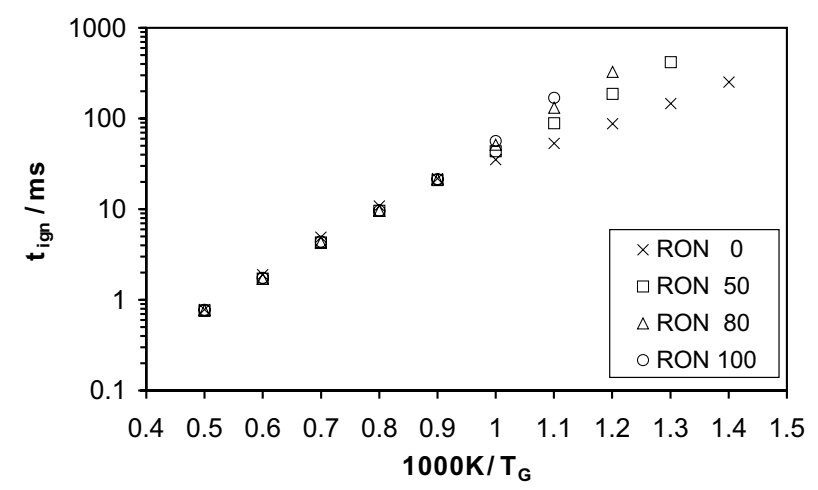

Fig. 1. Dependence of the ignition delay time on ambient temperature for $n$-heptane/iso-octane droplets with different research octane numbers $\left(p=8\right.$ bar, $\left.r_{\mathrm{D}}=200 \mu \mathrm{m}\right)$.

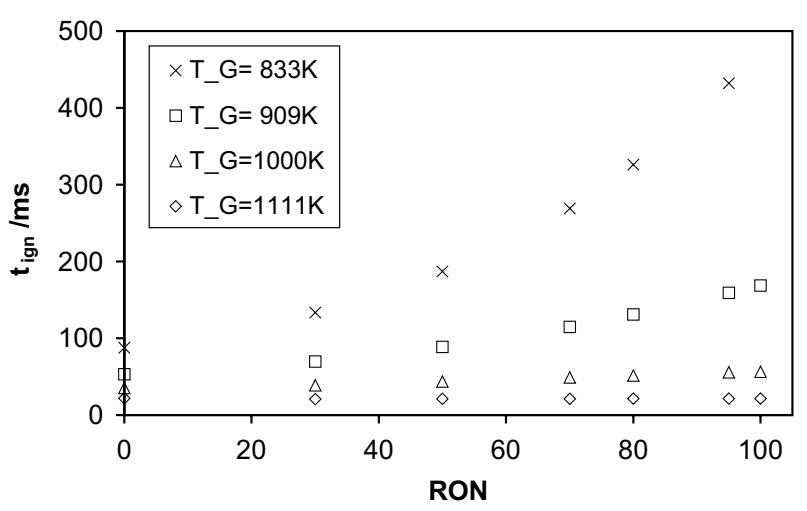

Fig. 2. Dependence of the ignition delay time on the research octane number $\left(p=8\right.$ bar, $\left.r_{\mathrm{D}}=200 \mu \mathrm{m}\right)$. numbers (RON). Below $1000 \mathrm{~K}$ the ignition delay times depend significantly on the RON. In Fig. 2 the dependence of the ignition delay time on the RON is shown. The ignition delay time increases with an increasing RON of the fuel droplet. It can be seen, that the slope of the curve, which represents the RON dependence, changes with the ambient temperature. With decreasing ambient temperatures the slope increases. At $1111 \mathrm{~K}$ the ignition delay time remains constant for different RONs. In contrast, at $833 \mathrm{~K}$ the ignition delay time increases by a factor 5 with a RON increasing from 0 to 95 . The temperature range from $700 \mathrm{~K}$ to $1000 \mathrm{~K}$ corresponds to the range of a negative temperature coefficient (NTC) for a homogeneous gas mixture of $n$-heptane and iso-octane in air [15]. In this region the influence of the composition of the mixture is strongest. Above $1000 \mathrm{~K}$ the ignition delay times of even the homogeneous gas mixtures are not much affected by the RON. The dependence of the ignition delay time on the RON below $1000 \mathrm{~K}$ is superimposed by the influence of the physical transport processes in the case of droplet ignition. The assimilation of the ignition delay times of different RONs is due to the fact, that $n$-heptane and iso-octane show a comparable vaporization behavior due to the similar physical properties. However, the influence of the RON on the ignition delay time is still evident, because in this range the ignition process is not only limited by transport processes, but also by the chemical kinetics.

The further studies of the influence of different physical parameters on the ignition behavior of $n$-heptane/isooctane fuel droplets are performed for a RON of 80 of the fuel droplets.

The duration of the initial heat-up period of the droplet is mainly governed by the initial droplet temperature [32]. This heat-up period necessarily affects the ignition delay. Therefore, the dependence of the ignition delay time on the droplet temperature is investigated. The influence of the initial droplet temperature on the ignition delay time can be seen in Fig. 3. The initial droplet temperature is varied from $300 \mathrm{~K}$ to $400 \mathrm{~K}$. To compare the results for the two different gas temperatures the ignition delay times

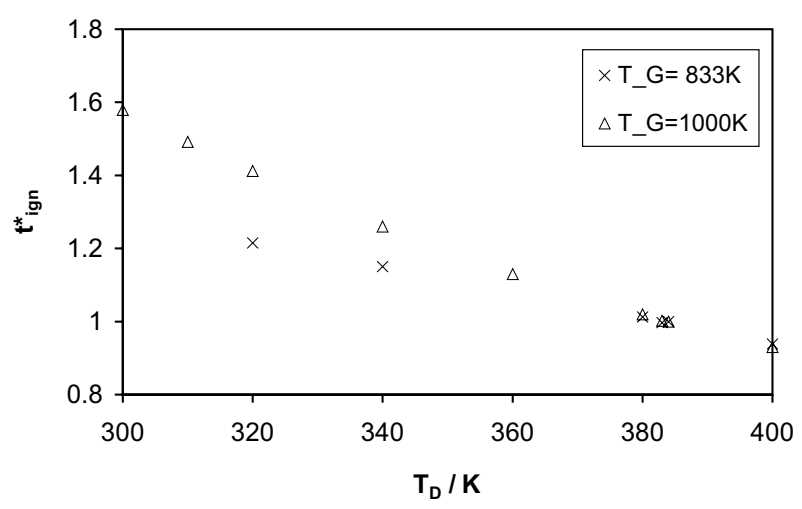

Fig. 3. Dependence of the normalized ignition delay time $t_{\mathrm{ign}}^{*}=t_{\mathrm{ign}}\left(T_{D}\right) / t_{\mathrm{ign}}\left(T_{\mathrm{D}}=384 \mathrm{~K}\right)$ on the initial droplet temperature $\left(p=8 \mathrm{bar}, r_{\mathrm{D}}=200 \mu \mathrm{m}\right)$. 
are normalized by dividing by the ignition delay time at $384 \mathrm{~K}: t_{\text {ign }}^{*}=t_{\text {ign }}\left(T_{\mathrm{G}}, T_{\mathrm{D}}\right) / t_{\text {ign }}\left(T_{\mathrm{G}}, T_{\mathrm{D}}=384 \mathrm{~K}\right)$. The ignition delay time increases with decreasing droplet temperature, as anticipated. Indeed, for a gas temperature of $1000 \mathrm{~K}$ the ignition delay time is reduced by a factor of almost 2 increasing the droplet temperature from $300 \mathrm{~K}$ to $400 \mathrm{~K}$. This dependence on the droplet temperature is minor for lower gas temperatures. For decreasing ambient temperatures the ignition process becomes more and more reaction controlled. Because the initial droplet temperature affects the transport processes rather than the chemical kinetics the influence of the droplet temperature on the ignition delay time decreases. Fig. 3 also shows that the influence of the droplet temperature on the ignition delay is decreasing with increasing droplet temperature. For higher initial droplet temperatures the influence of the initial droplet temperature on the ignition delay diminishes. As mentioned above, the ignition delay time is affected by the vaporization process of the fuel droplet. If the droplet temperature is low, the vaporization rate is limited by the vapor pressure of the droplet. If the droplet temperature is sufficiently high, the vaporization rate is governed by the heat of vaporization and the gas phase heat flux at the surface. Because the gas phase heat flux is dependent on the temperature gradient in the gas phase, it is almost not affected by the droplet temperature. Because of this insensitivity to the droplet temperature and because of the minor influence of the initial heat-up period for higher initial droplet temperatures the influence of the droplet temperature on the ignition delay time diminishes. For the remainder of the performed simulations the initial droplet temperature is set to $384 \mathrm{~K}$.

\subsection{Local ignition conditions}

The local conditions of the ignition of fuel droplets are investigated for different ambient temperatures. Fig. 4 shows the local air-fuel ratio $\lambda_{\text {loc }}$ for different ambient gas temperatures at the starting point of ignition. This starting point is characterized by the rise of the local temperature of $1 \%$ above the ambient temperature. The local

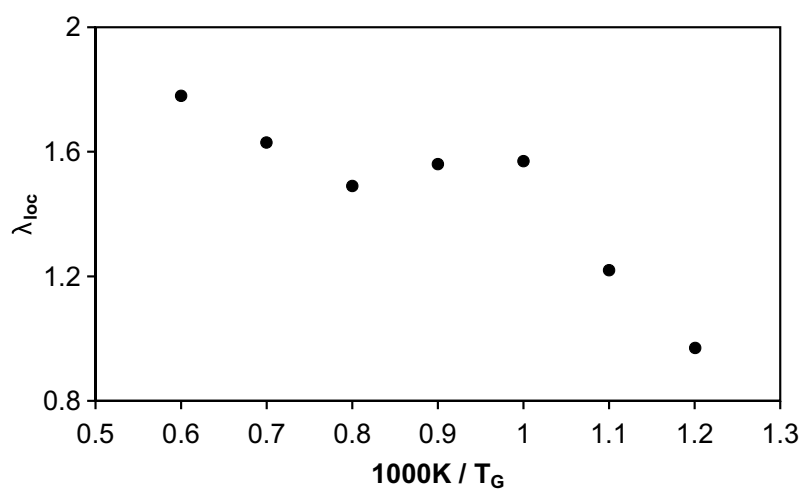

Fig. 4. Dependence of the local air-fuel ratio on the ambient gas temperature ( $p=8$ bar, $\left.r_{\mathrm{D}}=200 \mu \mathrm{m}\right)$. air-fuel ratio is determined via the element composition of hydrogen, carbon and oxygen because at this point of the overall process most of the initial fuel is already decomposed. Except for the lowest gas temperature of $833 \mathrm{~K}$ the local mixture at the point of ignition is lean. This is not necessarily the case for all ambient conditions. In fact, the hot ignition takes place even at rich local conditions for ambient temperatures belonging to the NTC-region [33]. Furthermore, this finding is very interesting, because the ignition delay time of a homogeneous air-fuel mixture at a given temperature decreases for decreasing air-fuel ratios $[34,35]$. It can be stated, that in the case of the auto-ignition of fuel droplets the gas temperature (which is spatially nonuniform) is governing the ignition process compared to the local mixture. The local air-fuel ratio of the igniting mixture essentially increases with increasing ambient temperature. It can be concluded that the local ignition conditions are principally getting leaner with increasing ambient temperature. Therefore, with increasing gas temperature the significance of the ambient gas temperature as the most important parameter of the ignition process also increases. The slight decrease of the air-fuel ratio in range from $1000 \mathrm{~K}$ to $1250 \mathrm{~K}$ can be addressed to the change of the active chemical pathways for chain branching [31].

\subsection{Sensitivity analysis of physical properties}

To justify the validity of the bicomponent model for real multicomponent gasoline fuel droplets the influence of different physical parameters is of importance. In the following the influence of different physical processes and properties of the liquid fuels on the ignition delay and the vaporization behavior is investigated. The results of simulations based on detailed modeling of the transport processes in the liquid phase are compared with the results assuming infinitely fast transport processes (distillation limited) and with the results assuming frozen transport processes (diffusion limited) in the liquid. The validity of these two commonly used approximations [3] is justified by comparing with the more realistic, detailed transport model used in this work. The distillation limited and the diffusion limited cases are modeled by an artificial scaling of the transport properties in the liquid phase by $10^{3}$ and $10^{-3}$, respectively. In Figs. 5-8 the solid lines (-) represent calculations using a detailed transport model, the dashed lines (---) comply with the distillation limited case and the dotted lines $(\cdots)$ stand for the diffusion limited case. In Fig. 5 profiles of the mole fraction of $n$-heptane inside the droplet at $t=0.1 \mathrm{~s}$ can be seen. In the distillation limited case the $n$-heptane is distributed equally inside the droplet because of the large transport coefficients and the mole fraction of $n$-heptane at the surface is overpredicted. In the case of detailed transport the profile displays the typical shape of the profile of the more volatile species of a bicomponent droplet. In the diffusion limited case most of the droplet still persists at the initial state. However, the mole fraction of $n$-heptane at the droplet surface is 


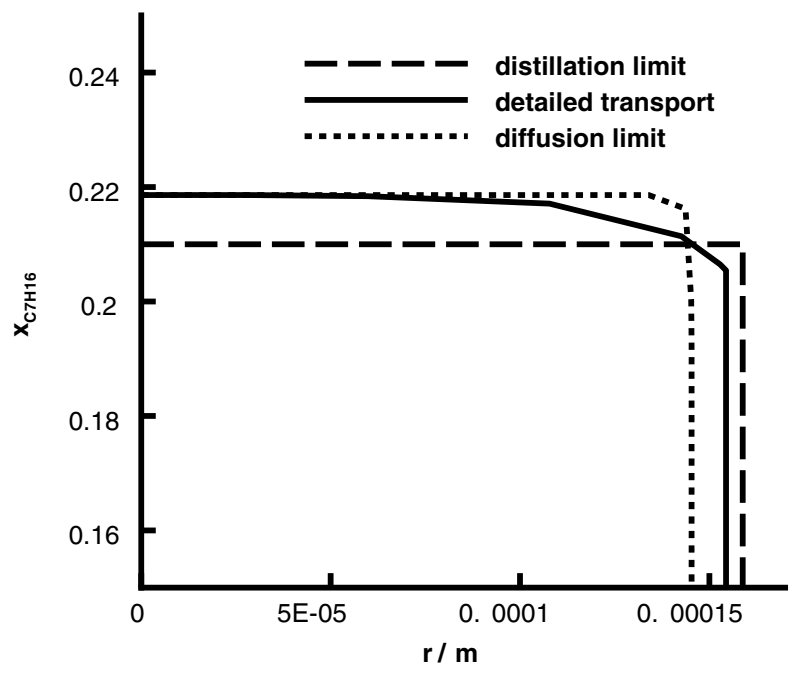

Fig. 5. Profiles of the mole fraction of $n$-heptane inside the droplet at $t=0.1 \mathrm{~s}\left(T_{\mathrm{G}}=1000 \mathrm{~K}, p=8 \mathrm{bar}, r_{\mathrm{D}}=200 \mu \mathrm{m}\right)$.
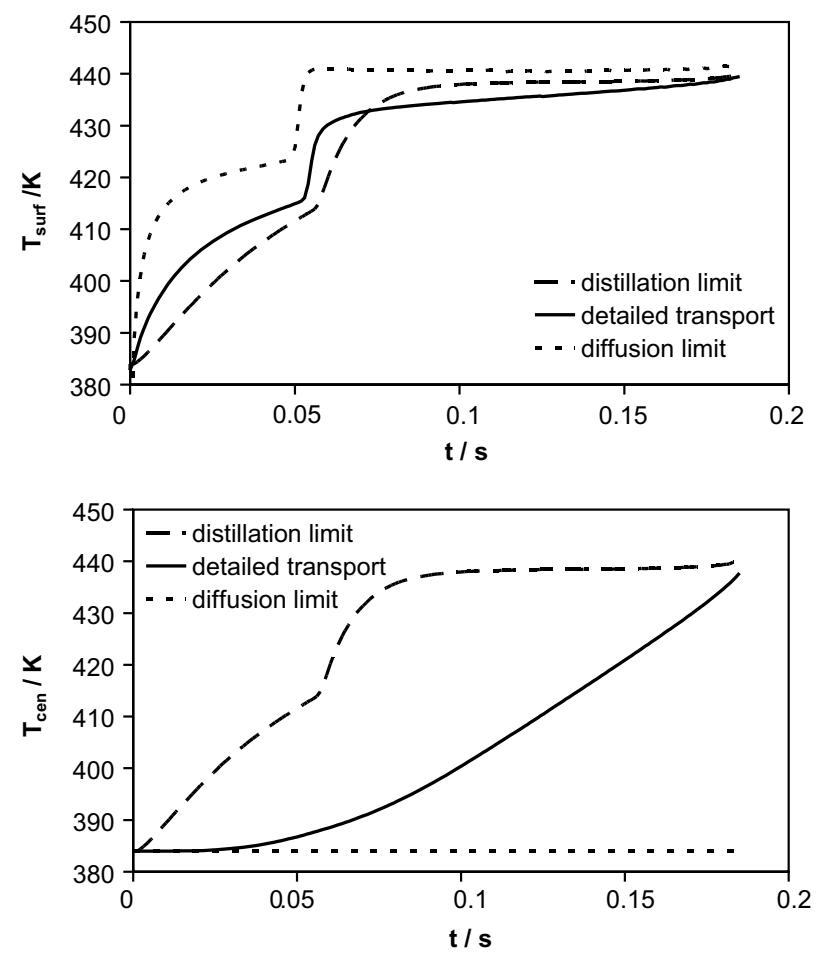

Fig. 6. Temporal evolutions of the temperature at the surface of the droplet (a) and at the center of the droplet (b) $\left(T_{\mathrm{G}}=1000 \mathrm{~K}, p=8 \mathrm{bar}\right.$, $\left.r_{\mathrm{D}}=200 \mu \mathrm{m}\right)$.

underestimated. The same behavior takes place regarding the droplet radius. It is overestimated in the case of distillation limit. This behavior originates in the underprediction of the vaporization rate, which is caused by the overprediction of the heat flux in the liquid phase. In contrast, in the diffusion limited case almost no heat conduction in the liquid phase appears and the vaporization rate is overestimated and therefore the droplet radius is underestimated. The differences in the profiles of the three test cases are not that large, but nevertheless general differences are evident. These findings coincide with the results of Makino and Law [10], who observed qualitatively the same behavior in the case of dodecane/hexadecane droplets. Fig. 6 shows the temporal evolutions of the temperatures at the surface and at the center of the droplet. The figures show the evolution from the beginning of the simulation to the complete vaporization of the droplet. In all three cases the droplet ignites at about $50 \mathrm{~ms}$. The typical step in the surface temperature due to ignition can be seen. In the distillation limited case the temperature on the surface at the beginning is lower than in the other cases due to the increased heat conduction from the surface to the center. Furthermore, the temperatures at the surface and at the center of the droplet almost coincide. Because of the reduced amount of conducted heat in the diffusion limited case the surface of the droplet is heated up too fast. When compared to the surface temperature, the temperature at the center of the droplet shows the typical delayed increase in the case of detailed transport [3,31]. In the distillation limited case the temperature at the center follows the surface temperature instantaneously. The center temperature remains almost constant during the vaporization of the droplet in the diffusion limited case due to the underestimated heat conduction.

In Fig. 7 the mole fractions at the surface and the fraction of vaporizing mass of $n$-heptane are shown for the three test cases. Because of the similar physical properties of $n$-heptane and iso-octane the differences in the profiles
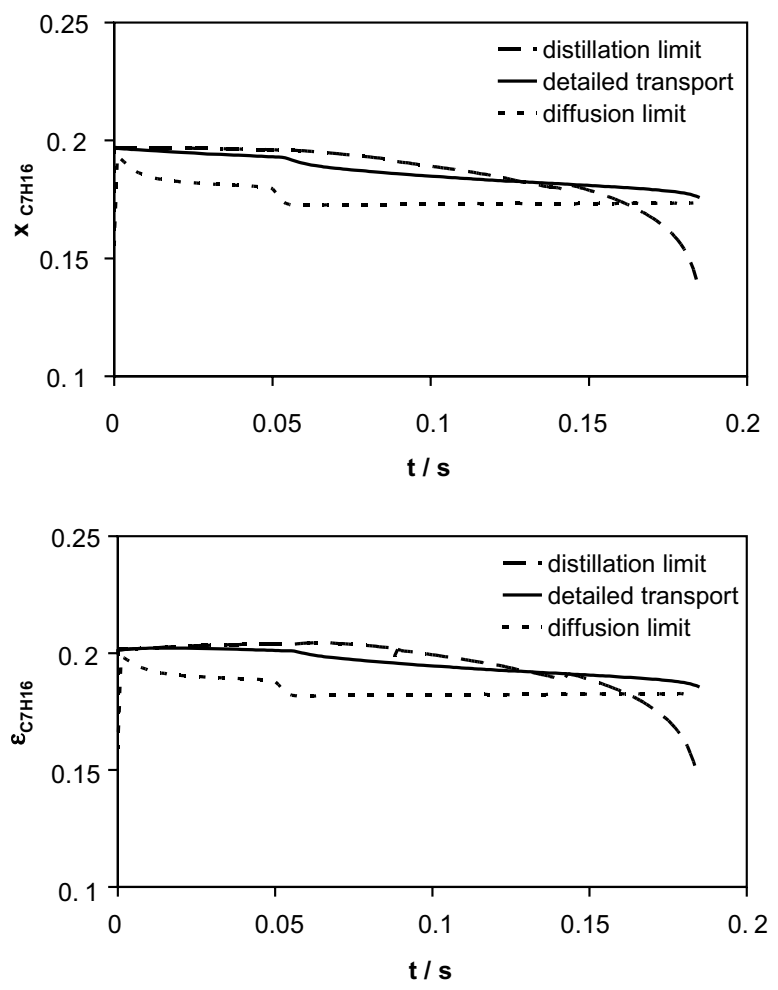

Fig. 7. Temporal evolutions of the mole fraction at the surface of the droplet (a) and the fraction of vaporizing mass (b) of $n$-heptane $\left(T_{\mathrm{G}}=1000 \mathrm{~K}, p=8\right.$ bar, $\left.r_{\mathrm{D}}=200 \mu \mathrm{m}\right)$. 


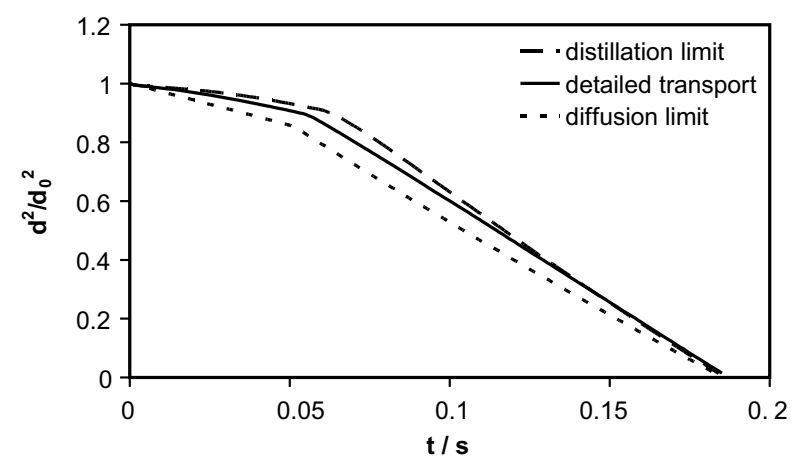

Fig. 8. Temporal evolutions of the droplet diameter $\left(T_{\mathrm{G}}=1000 \mathrm{~K}\right.$, $p=8$ bar, $\left.r_{\mathrm{D}}=200 \mu \mathrm{m}\right)$.

are within a range of 0.05 . However, the principal differences of the behavior of the three test cases can be observed. In all cases a decrease of the mole fraction of $n$-heptane with time is obtained due to the larger volatility. In the diffusion limited case the mole fraction of $n$-heptane decreases rapidly until $0.05 \mathrm{~s}$ and remains almost constant subsequently. In the distillation limited case the mole fraction and the fraction of vaporizing mass are overestimated for the more volatile species $n$-heptane until $0.14 \mathrm{~s}$. After that point both fractions decrease due to the global reduction of $n$-heptane in the droplet. This reduction is also caused by the larger volatility of $n$-heptane compared to iso-octane.

Fig. 8 shows the temporal evolutions of the droplet diameters for the three test cases, which all follow a $d^{2}$ law after ignition. As can be seen in Fig. 8 the ignition is slightly delayed in the distillation limited case compared to the detailed transport case. In the diffusion limited case the ignition delay time is slightly underestimated. But these variations of ignition delay time are minor. However, variations in the vaporization rates of about $15 \%$ are obtained. In the detailed transport case the vaporization rate is determined to $K=1.08 \mathrm{~mm}^{2} / \mathrm{s}$. This vaporization rate is overestimated by an amount of about $10 \%$ in the distillation limited case due to increased supplies of the more volatile $n$-heptane out of the inside of the droplet. In the diffusion limited case the behavior is contrary. The vaporization rate is underestimated by approximately $5 \%$.

Additionally, the sensitivity of the ignition delay time on the heat of vaporization is investigated. This is done by a brute force method, varying the heat of vaporization of one species $h_{\mathrm{vap}, i}$ by a factor of 1.5 . Here, the ambient conditions are given by an RON of 80 , a droplet radius of $200 \mu \mathrm{m}$, an initial droplet temperature of $384 \mathrm{~K}$ and an ambient gas temperature of $1000 \mathrm{~K}$. The ignition delay time does not change significantly $(\leqslant 0.2 \%)$, even if the heat of vaporization of $n$-heptane is varied by a factor of 1.5 . In contrast, if the heat of vaporization of iso-octane is varied, a noticeable variation of the ignition delay time can be detected. The relative sensitivity of the ignition delay time on the heat of vaporization of iso-octane in this case can be quantified by

$$
\begin{aligned}
\frac{\partial\left(\ln t_{\text {ign }}\right)}{\partial\left(\ln h_{\text {vap } \left., \mathrm{C}_{8} \mathrm{H}_{18}\right)}\right.} & =\frac{h_{\text {vap }, \mathrm{C}_{8} \mathrm{H}_{18}}}{t_{\text {ign }}} \cdot \frac{\partial t_{\text {ign }}}{\partial h_{\text {vap }, \mathrm{C}_{8} \mathrm{H}_{18}}} \\
& \approx \frac{h_{\text {vap }, \mathrm{C}_{8} \mathrm{H}_{18}}}{t_{\text {ign }}} \cdot \frac{\Delta t_{\text {ign }}}{\Delta h_{\text {vap }, \mathrm{C}_{8} \mathrm{H}_{18}}}=0.031 .
\end{aligned}
$$

This much larger dependence of the ignition delay time on the heat of vaporization of only iso-octane can be explained by the fact, that most of the total heat of vaporization is associated with iso-octane due to the large mole fraction of iso-octane of about 0.8 in the droplet.

The sensitivities of the ignition delay time on the vapor pressures of both fuels are investigated, too. This is done by varying the vapor pressure by a factor of 1.2. Sensitivities of

$$
\begin{gathered}
\frac{\partial\left(\ln t_{\text {ign }}\right)}{\partial\left(\ln p_{\text {vap }, \mathrm{C}_{7} \mathrm{H}_{16}}\right)} \approx \frac{p_{\text {vap }, \mathrm{C}_{7} \mathrm{H}_{16}}}{t_{\text {ign }}} \cdot \frac{\Delta t_{\text {ign }}}{\Delta p_{\text {vap }, \mathrm{C}_{7} \mathrm{H}_{16}}}=-0.091, \\
\frac{\partial\left(\ln t_{\text {ign }}\right)}{\partial\left(\ln p_{\text {vap }, \mathrm{C}_{8} \mathrm{H}_{18}}\right)} \approx \frac{p_{\text {vap }, \mathrm{C}_{8} \mathrm{H}_{18}}}{t_{\text {ign }}} \cdot \frac{\Delta t_{\text {ign }}}{\Delta p_{\text {vap }, \mathrm{C}_{8} \mathrm{H}_{18}}}=-0.032
\end{gathered}
$$

are derived. The sensitivities with respect to the vapor pressures exceed the sensitivities with respect to the heat of vaporization. The vapor pressure has a larger influence on the ignition delay than the heat of vaporization. Furthermore, it is striking, that the influence of the $n$-heptane is larger than the influence of iso-octane, despite of the significantly lower mole fraction of $n$-heptane. The ignition process appears to be governed by the more ignitable species $n$-heptane. However, an influence of the vapor pressure of iso-octane on the ignition delay time is also determined. In contrast to the ignition delay time, the vaporization process is only marginally affected by the modified vapor pressures. The vaporization rate of the droplet does not change significantly. Only the fraction of vaporizing mass of the species with the modified vapor pressure increases or decreases, respectively.

\section{Conclusions}

The auto-ignition process of single $n$-heptane/iso-octane droplets has been simulated numerically including detailed chemical and physical models. The mixture composition influences the ignition delay time at ambient temperatures below $1000 \mathrm{~K}$. The influence increases with decreasing temperature. At $833 \mathrm{~K}$ the ignition delay time increases by a factor of 5 with the RON increasing from 0 to 95 . Above $1000 \mathrm{~K}$ the ignition delay time is almost not affected by the mixture composition.

The investigation of the local ignition conditions of the process of droplet ignition shows that the ignition occurs at points of lean mixtures predominantly. The air-fuel ratio at the ignition location appears to increase with increasing ambient temperatures. This leads to the conclusion that the ambient gas temperatures is the dominant ambient parameter in the ignition process of fuel droplets.

A sensitivity analysis with respect to physical properties of the components of the fuel droplet shows only minor 
influences of transport coefficients of the liquid phase, like diffusion coefficients and heat conductivities, on the ignition delay time in accordance with the predictions of simple models. However, the temporal evolution and the vaporization process of the droplet is affected significantly. The sensitivity of the ignition delay time on the heat of vaporization shows only a noticeable value in the case of the species iso-octane, of which the fuel droplet mainly consists (note, the RON of 80). This variation of the heat of vaporization is assumed to influence the energy balance at the surface significantly. The vapor pressure is found to have a significant influence on the ignition delay time.

Calculations for droplets with smaller diameters suggest that at least the conclusions on the qualitative trends can be extended to smaller droplet sizes. A detailed investigation of the dependence on the droplet diameter is subject of future research. These findings lead to the conclusion, that gasoline droplets can be modeled by a mixture of $n$-heptane and iso-octane as a first approximation. However, further improvements have to be conducted to achieve models, which account for the specific physical and chemical properties of liquid surrogate droplets for a more reliable description of the ignition of gasoline droplets.

\section{Acknowledgments}

The authors thank the DFG for financial support in the frame of SFB 606. The authors thank Prof. F. Mauss and Dr. G. Moreac from the Division of Combustion Physics at the Lund Institute of Technology for allowing to use their $n$-heptane/iso-octane reaction mechanism.

\section{References}

[1] D.B. Spalding, The combustion of liquid fuels, Proc. Combust. Inst. 4 (1953) 847-864.

[2] F.M. Sparrow, J.L. Gregg, The variable fluid property problem in free convection, Trans. ASME 80 (1958) 879-886.

[3] C.K. Law, Recent advances in droplet vaporization and combustion, Prog. Energy Combust. Sci. 8 (1982) 171-201.

[4] W.A. Sirignano, Fuel droplet vaporization and spray combustion theory, Prog. Energy Combust. Sci. 9 (1983) 291-322.

[5] G.M. Faeth, Spray combustion phenomena, Proc. Combust. Inst. 26 (1996) 1593.

[6] G.S. Jackson, C.T. Avedisian, Modeling of spherically symmetric droplet flames including complex chemistry: effect of water addition on $n$-heptane droplet combustion, Combust. Sci. Technol. 115 (1996) 125-149.

[7] A.J. Marchese, F.L. Dryer, The effect of liquid mass transport on the combustion and extinction of biocomponent droplets of methanol and water, Combust. Flame 105 (1996) 104-122.

[8] A.J. Marchese, F.L. Dryer, R.O. Colantonio, V. Nayagam, Microgravity combustion of methanol and methanol/water droplets: Drop tower experiments and model predictions, Proc. Combust. Inst. 26 (1996) 1209-1217.

[9] A.J. Marchese, F.L. Dryer, R.O. Colantonio, Radiative effects in space-based methanol/water droplet combustion experiments, Proc. Combust. Inst. 27 (1998) 2627-2634.

[10] A. Makino, C.K. Law, On the controlling parameter in the gasification behavior of multicomponent droplets, Combust. Flame 73 (1988) 331-336.
[11] K. Okai, O. Moriue, M. Araki, M. Tsue, M. Kono, J. Sato, D.L. Dietrich, F.A. Williams, Pressure effects on combustion of methanol and methanol/dodecanol single droplets and droplet pairs in microgravity, Combust. Flame 121 (2000) 501-512.

[12] B.D. Shaw, H.A. Dwyer, J.B. Wei, Studies on combustion of single and double streams of methanol and methanol/dodecanol droplets, Combust. Sci. Technol. 174 (2002) 29-50.

[13] M. Takei, T. Tsukamoto, T. Niioka, Ignition of blended-fuel droplet in high-temperature atmosphere, Combust. Flame 93 (1993) 149-156.

[14] R. Stauch, S. Lipp, U. Maas, Detailed numerical simulations of the auto-ignition of single $n$-heptane droplets in air, Combust. Flame 145 (2006) 533-542.

[15] S.S. Ahmed, G. Moréac, T. Zeuch, F. Mauss, Reduced mechanism for the oxidation of the mixtures of $n$-heptane and iso-octane, in: Proceedings of the European Combustion Meeting, Louvain-laNeuve, 2005.

[16] R.B. Bird, W.E. Steward, E.N. Lightfoot, Transport Phenomena, John Wiley \& Sons, New York, Chichester, Brisbane, Toronto, Singapore, 1960.

[17] J.O. Hirschfelder, C.F. Curtiss, R.B. Bird, Molecular Theory of Gases and Liquids, John Wiley \& Sons, New York, 1964.

[18] R.C. Reid, J.M. Prausnitz, B.E. Poling, The Properties of Gases and Liquids, fourth ed., McGraw-Hill, 1989.

[19] R.W. Hankinson, G.H. Thomson, A new correlation for saturated densities of liquids and their mixtures, AIChE J. 25 (1979) 653-663.

[20] G. Latini, C. Baroncini, Effect of temperature and pressure on thermal conductivity of organic liquids, High Temperatures - High Pressures 15 (1983) 407-411.

[21] J.S. Rowlinson, Liquids and Liquid Mixtures, second ed., Butterworths, 1969.

[22] M.T. Tyn, W.F. Calus, Diffusion coefficients in dilute binary liquid mixtures, J. Chem. Eng. Data 20 (1975) 106-109.

[23] A. Letsou, L.I. Stiel, Viscosity of saturated nonpolar liquids at elevated pressures, AIChE J. 19 (1973) 409-411.

[24] A. Cuoci, M. Mehl, T. Paratico, T. Faravelli, E. Ranzi, Modeling of the evaporation and combustion of jet fuel droplets under microgravity conditions, in: Proceedings of the European Combustion Meeting, Louvain-la-Neuve, 2005.

[25] W. Wagner, J. Ewers, W. Pentermann, New vapour-pressure measurements and a new rational vapour-pressure equation for oxygen, J. Chem. Thermodyn. 8 (1976) 1049-1060.

[26] L. Riedel, Kritischer Koeffizient, Dichte des gesättigten Dampfes und Verdampfungswärme, Chemie Ingenieur Technik 26 (1954) 679-683.

[27] R.E. Thek, L.I. Stiel, A new reduced vapor pressure equation, AIChE J. 12 (1966) 599-603.

[28] D.S. Viswanath, N.R. Kuloor, On a generalized Watson's relation for latent heat of vaporization, Can. J. Chem. Eng. 45 (1967) 29-31.

[29] U. Maas, J. Warnatz, Ignition processes in hydrogen-oxygen mixtures, Combust. Flame 74 (1988) 53-69.

[30] P. Deuflhard, E. Hairer, J. Zugck, One-step and extrapolation methods for differential-algebraic systems, Numerische Mathematik 51 (1987) 501-516.

[31] J. Warnatz, U. Maas, R.W. Dibble, Combustion, third ed., Springer, Berlin, 2001.

[32] H. Nomura, Y. Ujiie, H.J. Rath, J. Sato, M. Kono, Experimental study on high-pressure droplet evaporation using microgravity conditions, Proc. Combust. Inst. 26 (1996) 1267-1273.

[33] S. Schnaubelt, Numerische Analyse des Selbstzündungsverhaltens einzelner Brennstofftropfen. PhD thesis, Universität Bremen, 2005.

[34] H.J. Curran, P. Gaffuri, W.J. Pitz, C.K. Westbrook, A comprehensive modeling study of $n$-heptane oxidation, Combust. Flame 114 (1998) $149-177$.

[35] B.M. Gauthier, D.F. Davidson, R.K. Hanson, Shock tube determination of ignition delay times in full-blend and surrogate fuel mixtures, Combust. Flame 139 (2004) 300-311. 